\title{
Psychopathy - A Clinical and Legal Dilemma
}

\author{
JOHN REED
}

Mentally disordered people who offend have been a cause for concern for a long time. As long ago as 1807 a Select Committee complained of the conditions in which some patients were held and recommended the establishment of a secure hospital, and in 1900 Thomas Holmes described his concerns at the "ever increasing army of the demented" coming before the magistrate's courts.

Reviews in the 1970s (Home Office/Department of Health and Social Security, 1975; Department of Health and Social Security, 1975) produced limited improvements in services for mentally disordered offenders, but continuing concern led to the establishment of a new review in 1990. The conclusions of that review (Department of Health/Home Office, 1992), with its 276 recommendations and six supporting reports (Department of Health/Home Office, 1993a-f) have been accepted by Ministers in the two departments as setting the direction in which they wish services to develop as resources allow. In September 1992 Ministers in the two departments set up further groups to review the provision of care in high security and the problems posed by people with severe personality disorders who fall within the legal category of psychopathic disorder.

\section{Recent reviews}

In 1986 Ministers in the two departments asked for a review of legal provisions relating to psychopathic disorder because of concern about the new power of Mental Health Review Tribunals to discharge restricted patients following the judgement of " $\mathrm{X}$ $v$. the UK" (Council of Europe, 1980) in the European Court of Human Rights. The working group (Department of Health and Social Security/Home Office, 1986) favoured the replacement of section 37 of the Mental Health Act 1983 (where it applied to those with psychopathic disorder) by a new provision which would enable the court to sentence the offender to a term of imprisonment, but to direct that he be admitted to hospital from court. But, on consultation, the majority view was that the case for legislative change had not been made.

More recently the case of Kim Kirkman has exemplified many of the problems relating to psychopathic disorder. Diagnosed as suffering from psychopathic disorder when he was a teenager, $\mathrm{Mr}$ Kirkman spent approximately 17 years mainly in special hospitals. Just prior to his discharge from a regional secure unit he killed a young woman and subsequently committed suicide. The report of the enquiry (West Midlands Regional Health Authority, 1991), into his case concluded that Mr Kirkman's disorder was never defined in terms which allowed the succession of psychiatrists who managed his treatment to share an understanding of what was wrong with him. The inquiry report added that "the use of the terms psychopathic disorder was not helpful in formulating treatment and rehabilitation plans."

Concerns have also been expressed about the effectiveness of treatments, the justification for the 'treatability' criteria in the 1983 Act and about the balance of responsibilities between the special hospitals and more local units (Chiswick, 1992; Coid, 1992; Robertson, 1992; Tennent et al, 1993).

The 1992 working group considered a wide range of issues relating to definition, treatment and management in prison and in hospital, research, and the law. The full report has been published (Department of Health/Home Office, 1994).

\section{The statutory definition}

As the 1975 Report of the Committee on Mentally Abnormal Offenders (the Butler Committee) pointed out

". . . From both the medical and legal points of view the historical development of the concept of psychopathy has given a rise to serious confusion ...."

In Britain, the 19th century concept of 'moral insanity' was enshrined in the category of 'moral imbecile' of the 1913 Mental Deficiency Act; and over time certain psychiatrists began to equate 'moral imbecile' with 'psychopathic personality'. The 1957 report of the Royal Commission on the Law Relating to Mental Illness and Mental Deficiency (the Percy Commission) was a key event. It commented

“. . . all psychopathic patients are to some extent lacking in appreciation of their own mental condition, or of the 
social or moral implications of their behaviour ... this is a typical characteristic of their disorder ..."

Following extensive consultation and Parliamentary debate, the term psychopathic disorder was included in the Mental Health Act 1959. It was defined as "a persistent disorder or disability of mind (whether or not including subnormality of intelligence) which results in abnormally aggressive or seriously irresponsible conduct on the part of the patient, and requires or is susceptible to medical treatment." With minor changes this definition was continued in the 1983 Act.

Equivalent categories to psychopathic disorder have emerged in some other Western jurisdictions. Psychopathic disorder is not, for example, included in the Scottish legislation as a separate category of mental disorder. The characteristics of the disorder are set out in the Scottish legislation, in similar terms to that used in England and Wales, but without the specific label. In the Mental Health (Scotland) Act 1984 mental disorder is defined as "mental illness or mental handicap, however caused or manifested" (section 1 (2)). Psychopathic disorder or personality disorder are not mentioned in the Act at all. However, when considering admission to hospital at Section 17 (1) (a) (i) the Act states "In cases where the mental disorder from which he suffers is a persistent one manifested only by abnormally aggressive or seriously irresponsible conduct ..." which suggests that the generic term mental disorder is intended to include those people who would be classified as psychopathically disordered in the English legislation. Under the Northern Ireland legislation people suffering from personality disorders are wholly excluded from compulsory detention for the treatment of that disorder.

\section{A case for change}

Over many years, and especially since the 1983 Act, there has been considerable debate over the statutory definition of psychopathic disorder. The complexity of the subject, and the general lack of agreement surrounding it, is illustrated by the results of a recent survey conducted of forensic psychiatrists in England, Scotland and Wales (Cope, 1993). The report commented:

“. . The crucial issue of whether [psychopathic disorder] should remain in the Mental Health Act produced no consensus view. Half said yes and half said no. Of those who said no, the split for and against the Scottish legislation was $60 / 40$. Less than half of all respondents qualified their responses by making alternative suggestions . ..."

\section{Options considered by the working group}

Three options for consideration emerged:

(a) to retain the existing statutory definition;

(b) to adopt the Scottish definition; or

(c) to replace the term 'psychopathic disorder' with 'personality disorder'.

\section{Retaining the existing term}

One view was that although the term 'psychopathic disorder' might be flawed, there was no obvious satisfactory alternative: extensive discussion in the past had only led to extensive disagreement and had achieved nothing. It might be sensible simply to leave the term as it stood.

Another view was that the term was useful. It could be used to describe a person's general conduct and offending behaviour and was reasonably meaningful not only to lawyers but also to administrators and Ministers who were required to make decisions in this area.

There was at least some measure of agreement between practitioners over common traits which comprise psychopathic disorder. A study (Tennent et al, 1990) involving psychiatrists, psychologists and probation officers, showed that these groups agreed that certain symptoms or statements were relevant to the description of psychopathic disorder and that the diagnosis was a meaningful one.

\section{The Scottish legislation}

Some commentators have previously suggested that the term 'psychopathic disorder' should remain in English law, but should not be defined in the statute. The Percy Commission considered the value of a definition:

". . . in our opinion it would do much more harm than good to try to include in the law a definition of psychopathic personality ..." It is far preferable that, in referring to various forms of mental disorder, the law should use general terms ... without trying to describe mental conditions in detail in semi-medical language..."

This reasoning might be extended so that psychopathic disorder was not included in the legislation at all, and a model similar to the Scottish one adopted. The 1983 Act was inconsistent about definitions. 'Mental illness' was not defined, whereas 'severe mental impairment', 'mental impairment', and 'psychopathic disorder' were. It would rationalise the position if there was a single category of 'mental disorder' in mental health legislation. 
However, there were potential disadvantages in such a proposal. The Butler Committee noted the apparently satisfactory experience in Scotland of the omission of psychopathic disorder from their corresponding statute. But as the Committee pointed out " . . . it is one thing to have an Act of Parliament which has never included the term, but another to withdraw it after it has been in a statute for 16 years ..." (now over 30 years). Removing a statutory definition might result in an even greater confusion and inconsistency in approach than at present.

\section{Replacing psychopathic disorder with the term personality disorder}

The term 'psychopathic disorder' was pejorative. But changing it to 'personality disorder' might not make any significant difference. Over time, 'personality disorder' might also come to be regarded as a convenient label to which disparaging assumptions were attached.

The Butler Report rehearsed the arguments which had been expressed in favour of deletion of the term and commented, inter alia:

". . . we have no doubt that it is highly undesirable to label people as psychopaths. This is especially true of juveniles, and psychiatrists are understandably reluctant to use the term psychopath of adolescents or to place them into recognised categories of mental disorder. Once applied the label sticks, and may serve to discourage a thorough investigation of a kind which might unmask a specific condition. On both counts research is impeded. To avoid the element of stigma, therefore, there is much to be said for urging Parliament formally to disown the term in the way that stigmatic terms such as 'lunatic', 'idiot' and 'imbecile' have already been disowned.

A further argument in favour of abandonment of the term is that the statutory classification should not only be understood by medical and legal practitioners but should also be in line with their current domestic and international uses ... psychopathic disorder is no longer a useful or meaningful concept; it is not associated with any of the sub-categories of mental disorder contained in the International Statistical Classification of Disease ... The class of persons to whom the term psychopathic disorder relates is not a single category identifiable by any medical, biological or psychological criteria."

The Butler Committee felt the solution might be to substitute in the relevant sections of the Act (then the 1959 Act) the recognised classifications of personality disorder which would subsume the category of psychopathic disorder. This would embrace those categories of cases where compulsory admission to hospital was indicated in the interest of the public and of the patient. The intention was that personality disorder, like mental illness, would not be defined in the Act because a short, usable definition was not possible.

\section{The working groups discussion}

The following main themes arose in the group's discussion:

(i) psychopathic disorder was a legal term which derived from the Mental Heath Acts rather than a medical diagnosis. Many psychiatrists attempted to translate the legal definition into clinical concepts of personality disorder, but the diverse meanings attached to psychopathic disorder often undermined the evaluation of treatment and rehabilitation programmes

(ii) the term embraced a range of severe personality disorders and the group labelled as psychopathically disordered was extremely heterogeneous. It could cover a spectrum from highly dangerous serial murderers and rapists to disturbed young women whose disorder manifested itself in repeated selfharm

(iii) the moral overtones attached to the term 'psychopath' impaired its usefulness. It was pejorative, and labelling individuals as such, especially at an early age, was detrimental, creating unfortunate, and often erroneous, self and public images. It was widely believed that individuals, once so labelled, were likely to be dealt with more severely in the criminal justice system and women labelled as psychopathically disordered were compulsorily detained in the hospital system to a disproportionate degree

(iv) being labelled as "a psychopath" could also be counter-productive in terms of care and treatment since some psychiatrists assumed that they were untreatable and likely to reoffend. As a consequence, people who might benefit from medical care were denied it and remained in prison or were left unsupported in the community.

The working group concluded that there was a persuasive argument for substituting the term 'personality disorder' for 'psychopathic disorder' in the statutory definition provided that 'personality disorder' was not defined further.

\section{The treatment of psychopathic disorder}

The group commissioned a review from Dr Dolan and Dr Coid (1993), covering a very wide range of psychological, physical, social and situational 
treatments. They concluded that there was no convincing evidence whether people suffering from psychopathic disorder could or could not be successfully treated. Some may respond to different treatments, in a range of settings, but it cannot at present be determined which treatment, in which setting, might be effective for which individual. More and better research was required in studies with properly assessed and defined samples, followed up for an adequate period and with validated measures of treatment effectiveness and outcome.

\section{Treatability}

Under the 1983 Act, the diagnosis of psychopathic disorder is not, in itself, sufficient to lead to a hospital disposal. People cannot be compulsorily admitted hospital either by means of a hospital order, or on transfer from prison, or under section 3 under the category psychopathic disorder unless it can be established that medical treatment is likely to alleviate or prevent deterioration of their condition. Under the 1983 Act 'medical treatment' is very broadly defined as including "nursing, and . . . care, habilitation and rehabilitation under medical supervision"' (section 145 (1)). Experience has shown that there are wide inconsistencies in the interpretation of the treatability criteria probably reflecting the lack of firm evidence of the benefits of treatment.

The group concluded that the treatability criteria should remain as they are. They are not in themselves restrictive, and there is no obvious satisfactory alternative. It may be that they help focus the minds of those responsible for making admission decisions.

\section{Court disposals}

The court disposal system should, so far as possible, reflect the present state of knowledge of treatment and management of psychopathic disorder. Given the uncertainties surrounding diagnosis and treatment, it is illogical and naive that courts should still routinely direct the admission to hospital of psychopathically disordered offenders in the anticipation that they would be successfully treated there and that they would not be discharged until they no longer represented a risk.

The group felt that the objections raised following the 1986 consultation exercise had become increasingly dated. One finding of the survey of forensic psychiatrists was

“. . . a substantial view . . .that indeterminate hospital orders for psychopathically disordered patients should be avoided and that transfer after sentence was a preferred option. This would enable the courts to impose the appropriate tariff for the offence."

\section{A hybrid order}

A problem with the suggestion in the College's study centred on the uncertainties and complications in securing transfer from prison under Sections 47 and 49 of the Act. The introduction into legislation of a 'hybrid order' similar to one option advocated by the 1986 working party might avoid these problems.

On the basis of assessment reports, the court would reach a view on whether or not hospital treatment was appropriate. If they decided it was not, the offender could, as now, receive a prison sentence. If the court had evidence to indicate that hospital treatment would be beneficial, it would still be able to make a hospital order under Section 37 of the Act, with or without restrictions. The 'hybrid order' would be reserved for those cases where there was substantial doubt over whether the offender would benefit from hospital treatment.

Under the 'hybrid order' the court would simultaneously impose a prison sentence representing an appropriate tariff for the offence and make a hospital order. Initially, the offender would be sent to hospital; and time spent there would count towards the sentence. If he responded to treatment, he could move through the hospital system as if subject to a hospital order. There would be no automatic assumption of remission to prison. He could be discharged direct from hospital on, or possibly even before, what would have been his release date. If his condition warranted it, he could remain in hospital as an unrestricted patient. (The system would, in a sense, be analogous to the management of cases under Section 47 and 49. However, if following a period in hospital, it became manifest that the offender was not going to benefit from treatment, or he refused to cooperate with his treatment programme, he could be remitted to prison under Section 50 of the Act to serve the remainder of his sentence.

\section{Advantages}

A 'hybrid order' might have the following advantages:

(i) it reflected the current state of knowledge of psychopathy. The fixing of a sentence by the court would provide a framework within which the psychiatric services would be able to provide flexible and appropriate treatment where necessary 
(ii) it was consistent with Government policy that mentally disordered of fenders should be dealt with through the hospital system wherever appropriate

(iii) the provision for the of fender to be remitted to prison at any stage would help to overcome the concerns of psychiatrists about being left with a potentially dangerous offender patient who was either untreatable or could not be offered any further treatment but whose discharge would pose risks to public safety

(iv) it might help to overcome the current haphazard selection and placement system, whereby an individual with psychopathic disorder might receive either a prison sentence or a hospital disposal without full assessment

(v) it should not expose the public to any greater risk. While some of fenders might be released earlier than if they had been admitted on an indeterminate hospital and restriction order a Mental Health Review Tribunal can currently discharge a patient at any time if it is satisfied that he no longer requires hospital treatment. Importantly, the Criminal Justice Act 1991 provided additional safeguards recognising that if the offence was sexual or violent, a longer sentence might be given to protect the public from serious harm. The Act also recognised that additional restrictions might need to be placed on the liberty of such offenders.

\section{Disadvantages}

There were also concerns about the proposal:

(i) it might be argued that it was wrong to treat offenders with psychopathic disorder differently from other mentally disordered offenders. Mentally disordered offenders who were treatable were dealt with through the hospital system and others were sent to prison. It would be inconsistent to introduce change which would mean that a psychopathically disordered individual would be suject to both treatment and punishment

(ii) the implicit lack of certainty in the order might cause difficulties in hospital treatment

(iii) the proposal would be inconsistent with current sentencing practice whereby an offender who was convicted of a serious offence and who was judged to be dangerous on account of his mental state was likely to receive a life sentence (iv) the present arrangements for restricted patients following discharge gave a structure to supervision and to health and social care which provided effective controls and safeguards.

The great majority of the group concluded that there was considerable merit in the idea of a hybrid order though concerns about principles and practicalities were also expressed. Such an order would be new to the legal and the mental health care systems; the proposal should be discussed more widely.

\section{Conclusion}

Psychopathic disorder is a very important subject; it presents the criminal justice system and the health and social care systems with some of their greatest challenges. The group's work has shown the extent of our ignorance in this area. If the report can help to stimulate debate on better ways forward it will have served its purpose.

\section{References}

Chiswick, D. (1992) Compulsory treatment of patients with psychopathic disorder: an abnormally aggressive or seriously irresponsible exercise? Criminal Behaviour and Mental Health, 2, 106-113.

CoID, J. (1992) Compulsory admission of dangerous psychopaths: psychiatrists are damned if they do and damned if they don't. British Medical Journal, 304, 1581-1582.

COPE, R. (1993) A survey of forensic psychiatrists' views on psychopathic disorder. Journal of Forensic Psychiatry, 4, 215-235.

COUNCIL OF Europe (1980) Application No 6998/75 by X against the United Kingdom.

Department of Health and Social Security (1975) Revised Report of the Working Party on Security in NHS Hospitals. London.

Department of Health/Home Office (1992) Review of Services for Mentally Disordered Offenders Final Summary Report. London: HMSO $\mathrm{Cm} 2088$.

- (1993a) Review of Services for Mentally Disordered Offenders, Vol 2. Service Needs (Reports of the Community, Hospitals and Prison Advisory Groups and a Steering Committee Overview). London: HMSO.

- (1993b) Review of Services for Mentally Disordered Offenders, Vol 3. Finance, Staffing and Training (Reports of the Finance, Staffing and Training Advisory Groups). London: HMSO. (1993c) Review of Services for Mentally Disordered Offenders, Vol 4. The Academic and Research Base (Reports of the Academic and Research Advisory Groups). London: HMSO.

(1993d) Review of Services for Mentally Disordered Offenders, Vol 5. Special Issues and Differing Needs (Report of the Official Working Group on Services for Mentally Disordered Offenders with Special Needs). London: HMSO. (1993e) Review of Services for Mentally Disordered Offenders, Vol 6. Race, Gender and Equal Opportunities. London: HMSO.

- (1993f) Review of Services for Mentally Disordered Offenders, Vol 7. People with Learning Disabilities (Mental Handicap) or with Autism. London: HMSO. 
(1994) Report of the Department of Health and Home Office Working Group on Psychopathic Disorder. London: Department of Health.

Department of Health and Social Securtty/Home Office (1986) Offenders Suffering from Psychopathic Disorder. London: DHSS/Home Office.

Dolan, B. \& Cold, J. (1993) Pyychopathic and Antisocial Personality Disorders: Treatment and Research Isowes. London: Gaskell.

Home Office/Department of Health and Social Securtry (1975)

Report of the Committee of Enquiry on Mentally Abnormal Offenders. London: HMSO.
Rosertson, G. (1992) Psychopathic disorder: objections to the present system. Criminal Behaviour and Mental Health, 2, 114-123.

Tennent, G., Tennent, D., Prins, D., et al (1990) Psychopathic disorder-a useful clinical concept? Medicine, Science and the Law, 30, 39-44.

et al (1993) Is paychopathic disorder a treatable condition? Medicine, Science and the Law, 33, 63-66. West Midlands Rboional Health Authortry (1991) Report of the Panel of Inquiry Appointed to Investigate the case of Kim Kirkman. Birmingham: West Midlands Regional Health Authority.

John Reed, FRCPsych, Department of Health, 133-155 Waterloo Road, London SE1 8UG

(First received 8 February 1995, final revision 31 July 1995, accepted 1 August 1995) 